\title{
Fetal membrane bacterial load is increased in histologically confirmed inflammatory chorioamnionitis: A retrospective cohort study ${ }^{\text {iै }}$
}

\author{
Rochelle Hockney $^{\mathrm{a}, \mathrm{b}}$, Gareth J. Waring ${ }^{\mathrm{d}}$, Gillian Taylor ${ }^{\mathrm{a}, \mathrm{b}}$, Stephen P. Cummings ${ }^{\mathrm{a}, \mathrm{b}}$, Stephen C. Robson ${ }^{\mathrm{d}}$, \\ Caroline H. Orr ${ }^{\mathrm{a}, \mathrm{b}, *}$, Andrew Nelson ${ }^{\mathrm{c}}$ \\ a School of Health and Life Sciences, Teesside University, Middlesbrough, TS1 3BX, UK \\ b National Horizons Centre, Teesside University, 38 John Dixon Lane, Darlington, DL1 1HG, UK \\ ${ }^{\text {c }}$ Faculty of Health and Life Sciences, Northumbria University, Newcastle, NE1 8ST, UK \\ ${ }^{\mathrm{d}}$ Institute of Cellular Medicine, Newcastle University, Newcastle, NE2 4HH, UK
}

\section{A R T I C LE IN F O}

\section{Keywords}

Histological chorioamnionitis

Placenta

Fetal membrane

Microbiome

Inflammation

Bacterial load

\begin{abstract}
A B S T R A C T
Introduction: It is widely debated whether fetal membranes possess a genuine microbiome, and if bacterial presence and load is linked to inflammation. Chorioamnionitis is an inflammation of the fetal membranes. This research focussed on inflammatory diagnosed histological chorioamnionitis (HCA) and aimed to determine whether the bacterial load in fetal membranes correlates to inflammatory response, including histological staging and inflammatory markers in HCA.

Methods: Fetal membrane samples were collected from patients with preterm spontaneous labour and histologically phenotyped chorioamnionitis (HCA; $n=12)$, or preterm $(n=6)$ and term labour without HCA ( $n=6)$. The bacterial profile of fetal membranes was analysed by sequencing the V4 region of the 16S rRNA gene. Bacterial load was determined using qPCR copy number/mg of tissue. The association between bacterial load and bacterial profile composition was assessed using correlation analysis.

Results: Bacterial load was significantly greater within HCA amnion ( $\mathrm{p}=0.002)$ and chorion $(\mathrm{p}=0.042)$, compared to preterm birth without HCA. Increased bacterial load was positively correlated with increased histological staging ( $p=0.001$ ) and the expression of five inflammatory markers; IL8, TLR1, TLR2, LY96 and IRAK2 $(\mathrm{p}=<0.050)$. Bacterial profiles were significantly different between membranes with and without HCA in amnion $(\mathrm{p}=0.012)$ and chorion $(\mathrm{p}=0.001)$, but no differences between specific genera were detected.

Discussion: Inflammatory HCA is associated with infection and increased bacterial load in a dose response relationship. Bacterial load is positively correlated with HCA severity and the TLR signalling pathway. Further research should investigate the bacterial load threshold required to generate an inflammatory response in HCA.
\end{abstract}

\section{Introduction}

Histological chorioamnionitis (HCA) is an inflammation of the fetal membranes [1], linked to adverse maternal and neonatal outcomes, including preterm birth [2], early onset sepsis and necrotising enterocolitis $[3,4]$. HCA incident rates are higher in preterm (15\%) compared to term (5\%) infants [5].

The origin of bacteria within the healthy fetal membrane microbiome is widely debated [6]. Conflicting studies have suggested that the placenta and fetal membranes are: (i) sterile [7-9], with any detection of bacteria linked to the mode of delivery [10]; (ii) typically sterile, with any bacteria detected arising due to co-existent maternal con- ditions, such as periodontal disease [10,11], vaginal infection [12], or gestational diabetes [13]; (iii) universally colonised with low abundant, non-pathogenic bacteria [14]. Although the existence of a unique microbiome in healthy membranes remains debated $[6,14]$, the healthy bacterial profile (composition and proportion of bacteria) is suggested to consist mainly of Escherichia spp. [14,15]. Alternatively, HCA membranes from preterm and term labour have presented with Ureaplasma spp. in $59 \%$ and $60 \%$ of cases respectively [2], suggesting any involvement is independent of gestation. Whilst other studies link HCA and inflammation with increased bacterial load (measurable quantity of bacteria) [16], with a positive correlation between the load of Prevotella spp. and HCA severity [17]. Alternatively, lower bacter-

Setting of work reported: National Horizons Centre, School of Health and Life Sciences, Teesside University, United Kingdom and Faculty of Health and Life Sciences, Northumbria University, United Kingdom.

${ }^{*}$ Corresponding author. School of Health and Life Sciences, Teesside University, Middlesbrough, TS1 3BX, UK.

E-mail addresses: r.hockney@tees.ac.uk (R. Hockney); gareth.waring@newcastle.ac.uk (G.J. Waring); taylor@tees.ac.uk (G. Taylor); s.cummings@tees.ac.uk (S.P. Cummings); s.c. robson@newcastle.ac.uk (S.C. Robson); c.orr@tees.ac.uk (C.H. Orr); andrew3.nelson@northumbria.ac.uk (A. Nelson) 
ial diversity has been implicated in preterm HCA membranes compared to controls [15], with monomicrobial characteristics in $83 \%$ of HCA cases [2]. In contrast, studies using shotgun and 16S rRNA gene sequencing have reported no distinct bacterial profiles in HCA membranes [6].

Careful consideration is required when elucidating the microbiome of fetal membranes due to low biomass characteristics. It is stated that external bacterial contribution will occur from the use of commercial kits and reagents, especially in low biomass samples [18]. Thus comparison of samples to DNA extraction kit negative controls is required. However, within the placental and fetal membranes this may also originate from contributing vaginal or skin bacteria during delivery or labour $[19,20]$.

Changes in inflammatory receptors and proinflammatory cytokines have been linked to HCA, including a two-fold increase in Toll-like Receptor 2 (TLR2) [21] and Interleukin 8 (IL8) [22], suggesting the involvement of bacteria as pro-inflammatory agents. However, the increase in cytokines may be indicative of active labour rather than being specific to HCA [23]. Inflammatory biomarkers are routinely investigated for risk of preterm birth [24] and clinical chorioamnionitis [25], but not yet applied to monitoring the risk or prediction of HCA.

\subsection{Aims and objectives}

Given HCA is a leading cause of preterm birth [26], research investigating the aetiology focused specifically on HCA is important. Although HCA and clinical chorioamnionitis overlap, the use of an established reproducible diagnostic criteria as a marker of fetal membrane infection ensures focus on HCA. This study aims to quantify the bacterial load, bacterial profile and diversity in fetal membranes to explore its relationship with the inflammatory response in HCA, including histological staging and inflammatory markers.

\section{Methods}

\subsection{Tissue selection and preparation}

Samples of placenta and fetal membranes (amnion and chorion) were collected, stored and phenotyped histologically using the established histological criteria by an independent clinician. Full criteria are described in Waring et al. (2015) [21]. The samples were utilised following informed consent for current research via a transfer agreement, with prior approval from Newcastle and North Tyneside 1 Research Ethics Committee (Ref: 10/H0906/71).

Fetal membrane samples were collected from 24 patients. Following histological diagnosis of HCA, patients were prospectively assigned to spontaneous preterm birth with histological chorioamnionitis (PTB + HCA, $\mathrm{n}=12$ ), spontaneous preterm birth without HCA (PTB-HCA, $\mathrm{n}=6$ ) and spontaneous term birth without HCA (TB-HCA, $\mathrm{n}=6$ ). Amnion and chorion were available for a subset of patients $(\mathrm{PTB}+\mathrm{HCA}=8$, PTB-HCA $=5$, TB-HCA $=0)$. In the remainder, amnion $(\mathrm{PTB}+\mathrm{HCA}=1$, PTB-HCA $=0$, TB-HCA $=0$ ), or chorion only were processed $(\mathrm{PTB}+\mathrm{HCA}=3$, PTB-HCA $=1$, TB-HCA $=6$ ). Samples were processed in triplicate and prepared with nine DNA extraction kit negative controls. Negative controls were processed identical to samples, with $\mathrm{dH}_{2} \mathrm{O}$ replacing tissue samples.

HCA was defined by standardised criteria, at maternal stage two and above [27]. Subchorionitis was defined as inflammatory stage one [27]. Labour was defined as the presence of regular spontaneous uterine contractions with progressive cervical dilation leading to delivery. Term was defined as a gestational age of $>37$ weeks, term patients were excluded if presenting with histologically indicated chorioamnionitis. Preterm samples were collected from patients delivering with a singleton pregnancy, in spontaneous labour at $<34$ weeks gestation, due to the inverse relationship between HCA and gestation [5]. Further sampling methods are presented in Waring et al. (2015) [21].

\subsection{Genomic DNA extraction}

Total genomic DNA was extracted from samples $(n=78)$ and negative controls $(\mathrm{n}=9$ ) using QIAamp Fast DNA Tissue Kit (Qiagen) as per manufacturer protocol. NanoDrop 1000 spectrophotometer (V3.8.1, Thermo Fisher) and agarose gel electrophoresis were used to assess yield, purity and quality of DNA prior to downstream analysis.

\subsection{Quantitative PCR}

Plasmid standards (16S rRNA gene) were generated using Escherichia coli genomic DNA and amplified via 27F (5'-AGAGTTTGATCMTGGCTCAG-3') and 1492R primers (5'-TACGGYTACCTTGTTACGACTT-3', Eurofins). PCR amplicons were purified (ExoSap-IT PCR clean up Kit; Thermo Fisher, Cat No:78201.1), before cloning into TOP10 competent E. coli cells (Thermo Fisher, Cat No:C404010) using PGEM-T Easy Vector System (Promega, Cat No:A1360). Plasmids were isolated using PureYield Plasmid MiniPrep (Promega, Cat No:A1223). A ten-fold serial dilution of pooled isolated plasmids was performed to create standard curves.

Absolute qPCR aimed to determine bacterial load within fetal membrane samples using BactQuant primers ( $F=5^{\prime}$-CCTACGGGDGGCWGCA-3' E. coli 341-356, R = 5'-GGACTACHVGGGTMTCTAATC-3' E. coli 786-806) and probe ((6FAM) 5'-CAGCAGCCGCGGTA-3' (MGBNFQ) E. coli 518-532; Eurofins) [28]. Reactions contained $1 \mu$ sample DNA, $1.8 \mu \mathrm{m}$ forward and reverse primers, $225 \mathrm{nM}$ probe, $0.05 \mu \mathrm{g} / \mu \mathrm{l}$ BSA, $4 \mathrm{mM} \mathrm{MgCl}_{2}$, 1\% formamide and 1X TaqMan Fast Advanced Master Mix (Thermo Fisher, Cat No:4444557) in a total of $10 \mu$ l. Extracted DNA from samples and standards, plus controls of DNA extraction kit negatives and no template controls (NTC) were assayed in triplicate using CFX Connect Real Time System (Biorad, CFX Manager V3.1). BactQuant protocol was used [28], with an optimised annealing temperature of $55^{\circ} \mathrm{C}$.

\subsection{Expression of inflammatory markers}

The expression of TLR signalling pathway components was undertaken by relative qPCR and has been reported previously [21]. Briefly, genes showing significant change in expression on signalling arrays were individually validated using qPCR. TaqMan GAPDH was selected as an endogenous control due to consistent results as a house-keeping gene in the signalling array study. Each assay was performed in triplicate. Findings indicated the involvement of TLRs in HCA, initiating this research into bacterial involvement in HCA.

\subsection{Microbiota analysis}

Sequencing of DNA samples and negative controls was performed by NU-OMICs (Northumbria University, UK) as described previously [29], with the universal 16S rRNA gene primer specific to the V4 region [30]. A sequencing negative control and ZymoBIOMICS mock microbial community standard were processed alongside samples.

Package DADA2 1.4 [31] and Bioconductor (Version 2) [32] were used to trim and filter MiSeq data with a q score of $<30$, to ensure consistent length and high-quality reads [32]. Forward and reverse paired strands were merged and clustered into Amplicon Sequence Variants (ASVs) [33], with clusters differentiated by one nucleotide, for high resolution bacterial detection [33]. Chimeras were removed using remove BimeraDenovo, before assigning taxonomy and constructing a phylogenetic tree using RDP14 reference database [34]. 


\subsection{Statistical analyses}

Patient characteristics were analysed using the package TableOne in $\mathrm{R}$ [35]. Outcomes were assessed between subgroups using Kruskal Wallis and Wilcoxon Rank-Sum, with categorical data analysed by Pearson's Chi-Squared or Fisher's Exact [35].

For the analysis of bacterial load, copy numbers of 16S rRNA gene/ $\mathrm{mg}$ of tissue were calculated and $\log _{10}$ transformed. Comparison between conditions were conducted using Kruskal Wallis followed by Pairwise Wilcoxon Rank-Sum and visualised with ggplot2 [35]. The correlation of bacterial load to histological staging or inflammatory marker fold change was performed using linear regression [36] and Spearman's Rho Bonferroni, respectively [35].

For bacterial abundance, PERMANOVA (GUniFrac) and Shannon Alpha diversity were explored using Phyloseq [37]. Shannon Alpha diversity assesses local bacterial composition in a sample, determining variety and number of bacterial genera [38], with this method beneficial for low read count and low abundance samples [38]. Whereas beta diversity matrices (PERMAONVA GUniFrac) compare community level similarity across different samples and subgroups [39]. Further univariate analysis applied false discovery rate corrections (FDR). FDR controls for multiple comparisons and allows understanding of type one errors or false-positive results [39]. Comparison between conditions and the above findings were performed by Kruskal Wallis and Pairwise Wilcoxon Rank-Sum, before visualising with ggplot2 [35].

\section{Results}

Participant characteristics are shown in Table 1. No differences were identified between participants in the PTB + HCA and PTB-HCA subgroups other than HCA stage $(\mathrm{p}=<0.001)$ and grade $(\mathrm{p}=0.036)$. Although the focus of this research was HCA, one patient with inflammatory diagnosed HCA also presented with clinical signs of chorioamnionitis.

\subsection{Bacterial load is increased with HCA}

Fetal membranes from participants with PTB + HCA displayed a greater mean bacterial load than those with PTB-HCA $\left(3.4 \log _{10} / \mathrm{mg}\right.$ vs $2.4 \log _{10} / \mathrm{mg}, \mathrm{p}=<0.001$ ). When investigating individual membranes; significantly greater bacterial load was evident in PTB + HCA amnion tissues compared to PTB-HCA amnion tissues (3.3 $\log _{10} / \mathrm{mg}$ vs 2.4 $\log _{10} / \mathrm{mg}, \mathrm{p}=0.002$; Fig. $1 \mathrm{~A}$ ). In chorion tissues, PTB + HCA bacterial loads were also greater compared with PTB-HCA $\left(3.3 \log _{10} / \mathrm{mg}\right.$ vs $\left.2.3 \log _{10} / \mathrm{mg}, \mathrm{p}=0.042\right)$ and TB-HCA $\left(3.3 \log _{10} / \mathrm{mg}\right.$ vs $2.3 \log _{10} / \mathrm{mg}$, $\mathrm{p}=0.031$ ). No difference was found between PTB-HCA and TB-HCA chorion ( $\mathrm{p}=0.937$, Fig. 1B).

\subsection{Bacterial load positively correlates with histological staging in HCA}

There was a significantly positive correlation between bacterial load and histological staging of membrane inflammation ( $p=0.001$; Fig. 2), with higher bacterial load related to higher stage of HCA.

\subsection{Bacterial load is positively correlated with inflammatory gene expression}

Bacterial loads in amnion and chorion were significantly correlated to the expression of some inflammatory markers (Table 2). In the chorion, bacterial load was positively correlated with IL8 ( $p=0.002)$, LY96 ( $\mathrm{p}=0.003)$, IRAK2 $(\mathrm{p}=0.004)$, TLR2 $(\mathrm{p}=0.005)$ and TLR1 $(\mathrm{p}=0.013)$. In the amnion, only IL8 was significantly correlated with bacterial load $(\mathrm{p}=0.050)$.

\subsection{There is varied range of bacterial genera present irrespective of histological phenotype}

The bacterial profile was significantly different between groups of PTB + HCA, PTB-HCA and TB-HCA in both chorion $\left(\mathrm{R}^{2}=0.2\right.$, $\mathrm{p}=0.010)$, and amnion $\left(\mathrm{R}^{2}=0.2, \mathrm{p}=0.012\right.$; Fig. $1 \mathrm{C}$ and $\left.1 \mathrm{D}\right)$. However, no specific genera were statistically significantly different when comparing between groups.

Table 1

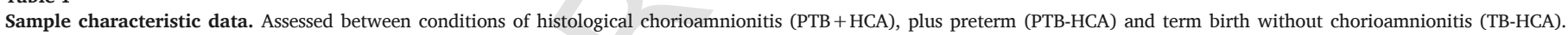

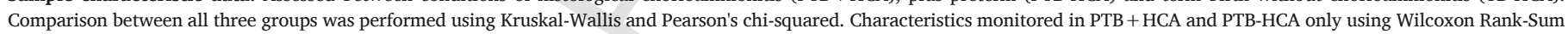
and Fisher's exact test. Significance threshold for comparisons was $\mathrm{p}=\leq 0.05$ (bold and italics). Results are displayed as $\mathrm{n}$ (\%) or mean (SD). Data unavailable for term subjects (-).

\begin{tabular}{|c|c|c|c|c|c|}
\hline Characteristic & $\begin{array}{l}\text { Preterm birth with HCA } \\
(\text { PTB + HCA }) \\
(\mathrm{n}=12)\end{array}$ & $\begin{array}{l}\text { Preterm birth without HCA } \\
\text { (PTB-HCA) } \\
(\mathrm{n}=6)\end{array}$ & $\begin{array}{l}\text { Term birth without HCA } \\
\text { (TB-HCA) } \\
(\mathrm{n}=6)\end{array}$ & $\begin{array}{l}\text { p. value } \\
\text { PTB + HCA } \\
\text { PTB-HCA } \\
\text { TB-HCA }\end{array}$ & $\begin{array}{l}\text { p. value РТВ + HCA } \\
\text { PTB-HCA }\end{array}$ \\
\hline Gestational age (mean (SD)) & $29.6(2.9)$ & $29.7(4.0)$ & $40.4(0.6)$ & 0.001 & 0.779 \\
\hline Birthweight (mean (SD)) & $1387.0(504.4)$ & $1736.7(402.3)$ & $3250.0(495.6)$ & 0.001 & 0.291 \\
\hline Maternal age (mean (SD)) & $29.3(8.0)$ & $27.0(5.5)$ & $32.2(6.0)$ & 0.411 & 0.511 \\
\hline BMI (mean(SD)) & $22.0(9.2)$ & $22.5(4.5)$ & $22.3(2.1)$ & 0.515 & 0.580 \\
\hline Smoker & $4.0(33.3)$ & $2.0(33.3)$ & 0.0 & 0.329 & 0.806 \\
\hline \multicolumn{6}{|l|}{ Mode of delivery } \\
\hline Spontaneous vaginal & $8.0(66.7)$ & $5.0(83.3)$ & - & - & 1.000 \\
\hline Caesarean section & $4.0(33.3)$ & $1.0(16.7)$ & - & - & \\
\hline PPROM & $9.0(75.0)$ & $3.0(50.0)$ & - & - & 0.330 \\
\hline $\begin{array}{l}\text { Interval from PPROM to labour } \\
\text { (mean(SD)) }\end{array}$ & $7.0(3.2)$ & $1.7(0.6)$ & - & - & 0.051 \\
\hline Previous preterm birth & $5.0(41.7)$ & $1.0(16.7)$ & - & - & 0.600 \\
\hline Antibiotics & $7.0(58.3)$ & $4.0(66.7)$ & - & - & 0.604 \\
\hline Antenatal corticosteroids & $11.0(91.7)$ & $5.0(83.3)$ & - & - & 1.000 \\
\hline HCA Stage (mean (SD)) & $2.2(0.4)$ & $1.0(0.0)$ & - & - & $<0.001$ \\
\hline HCA Grade (mean (SD)) & $1.6(0.5)$ & $1.0(0.0)$ & - & - & 0.036 \\
\hline $\begin{array}{l}\text { Clinical cases of } \\
\text { chorioamnionitis }\end{array}$ & $1.0(8.3)$ & $0(0.0)$ & - & - & 0.556 \\
\hline
\end{tabular}


A

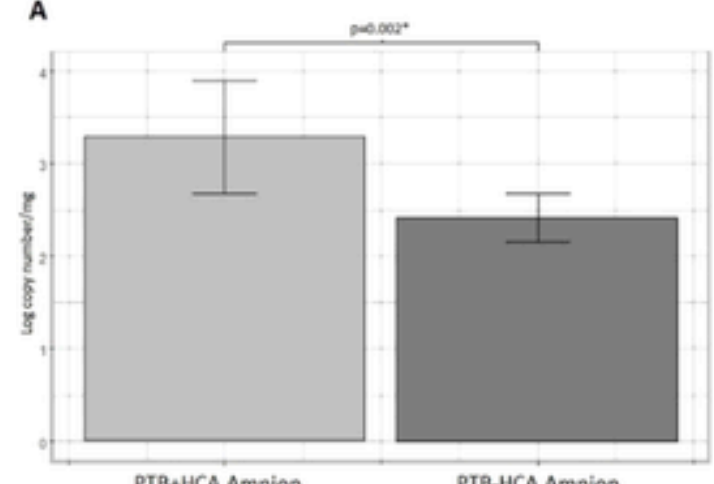

PTB+HCA Amnion

PTB-HCA Amnion

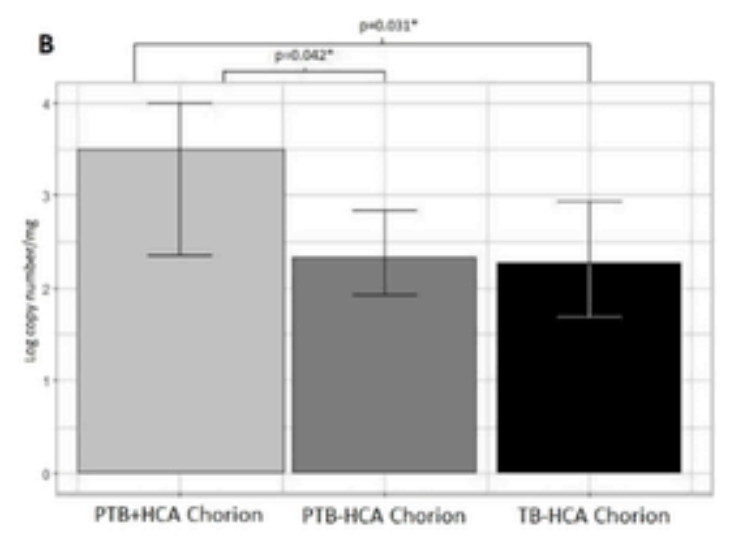

C

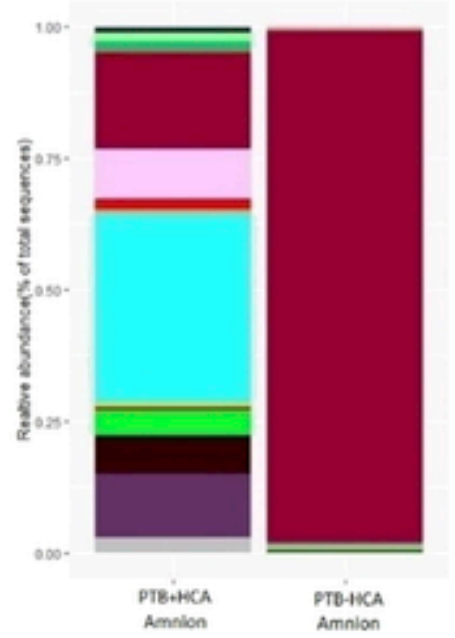

D

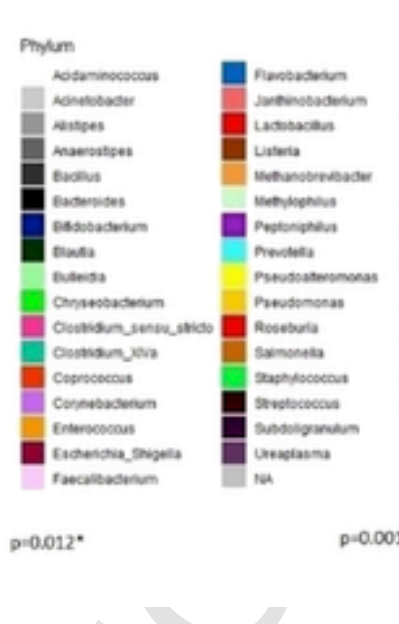

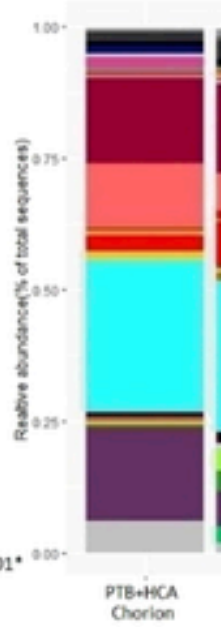



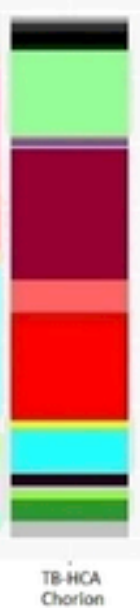

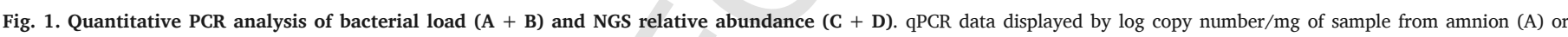

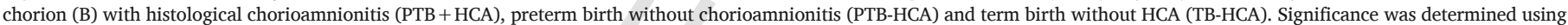

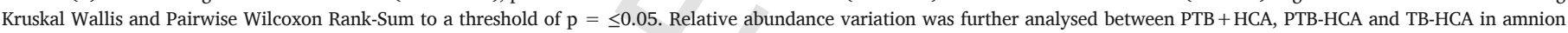

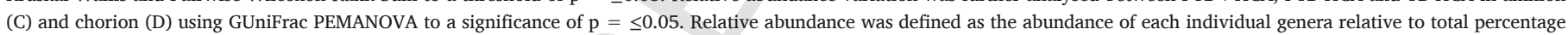
of bacterial genera.

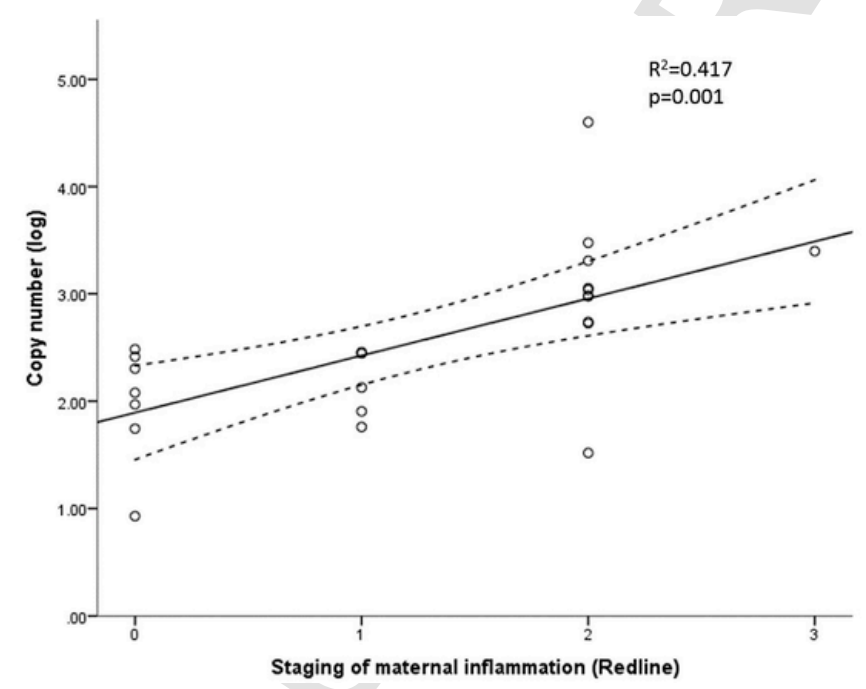

Table 2

Correlation of bacterial load against inflammatory gene fold change. Significant differences displayed individually by amnion or chorion were determined using Spearman's Rank Bonferroni ( $\mathrm{p}=\leq 0.05$, bold and italics).

\begin{tabular}{|c|c|c|c|c|c|}
\hline Amnion & & & Chorion & & \\
\hline $\begin{array}{l}\text { Inflammatory } \\
\text { marker }\end{array}$ & $\begin{array}{l}\text { Spearman's } \\
\mathrm{R}_{\mathrm{s}}\end{array}$ & $\begin{array}{l}p . \\
\text { value }\end{array}$ & $\begin{array}{l}\text { Inflammatory } \\
\text { marker }\end{array}$ & $\begin{array}{l}\text { Spearman's } \\
\mathrm{R}_{\mathrm{s}}\end{array}$ & $\begin{array}{l}p . \\
\text { value }\end{array}$ \\
\hline TLR1 & 0.346 & 0.247 & TLR1 & 0.538 & 0.013 \\
\hline TLR2 & 0.489 & 0.093 & TLR2 & 0.600 & 0.005 \\
\hline TLR4 & 0.363 & 0.224 & TLR4 & 0.147 & 0.524 \\
\hline TLR6 & -0.093 & 0.764 & TLR6 & 0.261 & 0.252 \\
\hline SARM1 & -0.302 & 0.315 & SARM1 & 0.117 & 0.613 \\
\hline MyD88 & 0.346 & 0.247 & MyD88 & 0.061 & 0.793 \\
\hline LY96 & 0.357 & 0.232 & LY96 & 0.631 & 0.003 \\
\hline IL8 & 0.560 & 0.050 & IL8 & 0.655 & 0.002 \\
\hline IRAK2 & 0.489 & 0.093 & IRAK2 & 0.612 & 0.004 \\
\hline HMGB1 & 0.050 & 0.878 & HMGB1 & 0.284 & 0.211 \\
\hline SIGIRR & 0.368 & 0.216 & SIGIRR & 0.139 & 0.549 \\
\hline TIRAP & 0.088 & 0.778 & TIRAP & 0.234 & 0.306 \\
\hline
\end{tabular}

Fig. 2. Linear regression analysis. Analysis between bacterial load (log copy number) and histological staging of membrane inflammation using linear regression to a threshold of $\mathrm{p}=\leq 0.05$. 


\subsection{Alpha diversity does not differentiate between conditions}

PTB + HCA samples had the higher overall bacterial diversity (0.7), with PTB-HCA (1.0) and TB-HCA lower (1.1), yet no difference between groups $(p=0.220)$. When analysing by tissue type, although diversity was highest in both PTB + HCA amnion and chorion the differences across conditions were not statistically significant (Fig. 3).

3.6. Non-HCA samples and negative controls differ in bacterial profiles and specific genera, but not bacterial load

Sequencing and qPCR results from preterm and term patients without HCA were compared to negative controls to investigate genuine microbiota detection from non-HCA fetal membranes. The overall bacterial profiles were significantly different between non-HCA samples and negative controls $\left(\mathrm{r}^{2}=0.2, \mathrm{p}=<0.001\right.$; Fig. 4A). Further significance was detected between specific genera. Dorea was detected in negative controls (average read number $=163.1$ ), but not detected in non-HCA samples ( $\mathrm{p}=0.001, \mathrm{FDR}=0.027$ ). The mean abundance from Pseudomonas was significantly greater in negative controls (91.7) compared to PTB-HCA (4.8) and TB-HCA samples (2.8; p $=0.002$, FDR $=0.030$ ). Escherichia was significantly reduced in TB-HCA (45.5), compared to similar levels from PTB-HCA (2295.2) and negative controls (2237.2; $\mathrm{p}=<0.001, \mathrm{FDR}=<0.001)$. There was no variation in Lactobacillus $(\mathrm{p}=0.050, \mathrm{FDR}=0.303)$, Ureaplasma $\quad(\mathrm{p}=0.073$, $\mathrm{FDR}=0.308)$ or Prevotella $(\mathrm{p}=0.608, \mathrm{FDR}=0.730)$.

No significant difference was detected when comparing bacterial loads of non-HCA samples to negative controls $\left(2.4 \log _{10}, \mathrm{p}=0.9277\right.$; Fig. 4B). For clarification, no bacterial loads were detected from NTCs for all qPCR experiments.

\section{Discussion}

\subsection{Main findings}

Findings indicate that a greater bacterial load is associated with HCA and a greater bacterial load is positively correlated with greater histological staging and inflammatory markers. This supports the suggestion that bacteria act as inflammatory agents in a dose dependent manner in HCA.

A

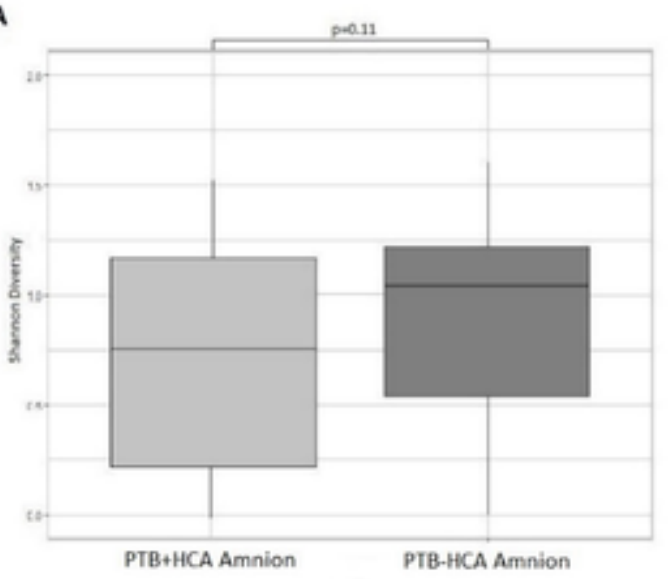

\subsection{Interpretation}

The key finding of this study is that inflammation in the fetal membranes is associated with presence of bacterial infection and increased bacterial load. Previous research supports the theory that bacterial presence is linked to HCA $[19,20]$, with $97 \%$ of HCA cases presenting with bacterial colonisation [40], leading to microbial associated inflammation of the amnion [40]. Bacterial loads of up to 5.2 $\log _{10}$ copies/ $\mu \mathrm{l}$ have also been detected in fetal membranes with HCA [16], consistent with our findings. In contrast, Romero et al. (2014) [41] detected bacteria in $11 \%$ of amniotic fluid samples with PTB and intra-amniotic inflammation, compared to $26 \%$ with a sterile inflammatory response [41]. Studies have linked HCA to bacterial loads of specific genera, including Prevotella [17] and Ureaplasma [40]. The expansion of Ureaplasma in HCA was supported here yet did not reach significance. Although inflammation has not been attributed to specific organisms here, investigation of the species-specific bacterial load may play a role in this multifactorial inflammatory condition. As the likely passage of bacteria is ascending, lower bacterial load would be expected in the chorion. Although consistent bacterial load was present across membranes with HCA here, the inflammatory response may differ across membranes impacting clinical relevance and requiring further investigation.

Findings show that bacterial load is positively correlated with HCA severity in a dose dependent manner. This observation is supported across multiple methodologies and tissue types [19,42,43]. Research on chorioamniotic membranes has suggested that as HCA severity increased, so did bacterial load [19]. Bacteria were detected in $87 \%$ of membranes with stage three HCA, compared to $33 \%, 40 \%$ and $60 \%$ with stage zero, one and two HCA, respectively [19]. In amniotic fluid, bacterial load was $10^{6}$ copies $/ \mathrm{ml}$ with stage three HCA, compared to $10^{3}$ copies/ml in stages zero, one and two [42]. However, the link between bacterial load and inflammation in HCA has been questioned, with the suggestion that any increase in bacterial load or inflammation is due to active labour rather than specific to HCA [23]. In this study all patients recruited were in spontaneous active labour, limiting variation and controlling for vaginal contamination, and the relationship between histological grading and bacterial load remained consistent. Although the focus here was on preterm patients, studies addressing HCA at term are required.

Data suggests that bacterial load correlates to inflammation via activation of the TLR signalling pathway. We have previously reported an increase in gene expression of TLR1 and TLR2 in HCA in

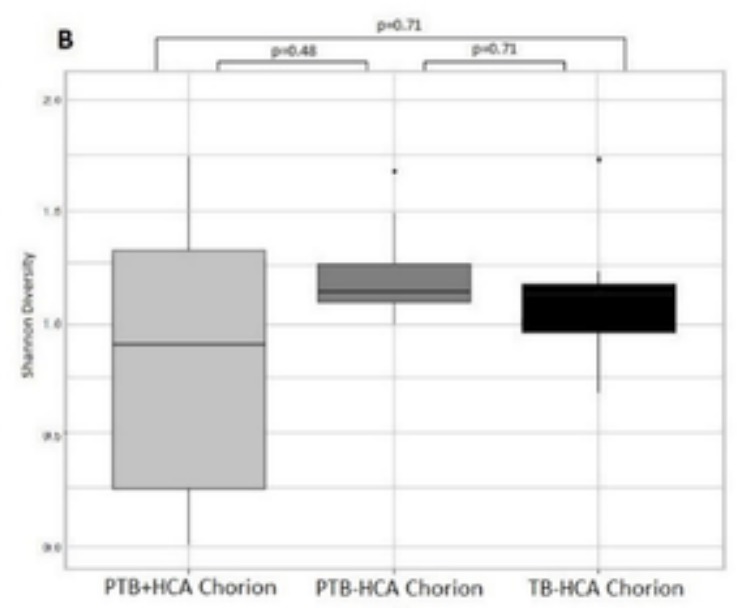


with chorioamnionitis (PTB + HCA), preterm birth without chorioamnionitis (PTB-HCA) and term birth without chorioamnionitis (TB-HCA) to a threshold of $\mathrm{p}=\leq 0.05$. 
A

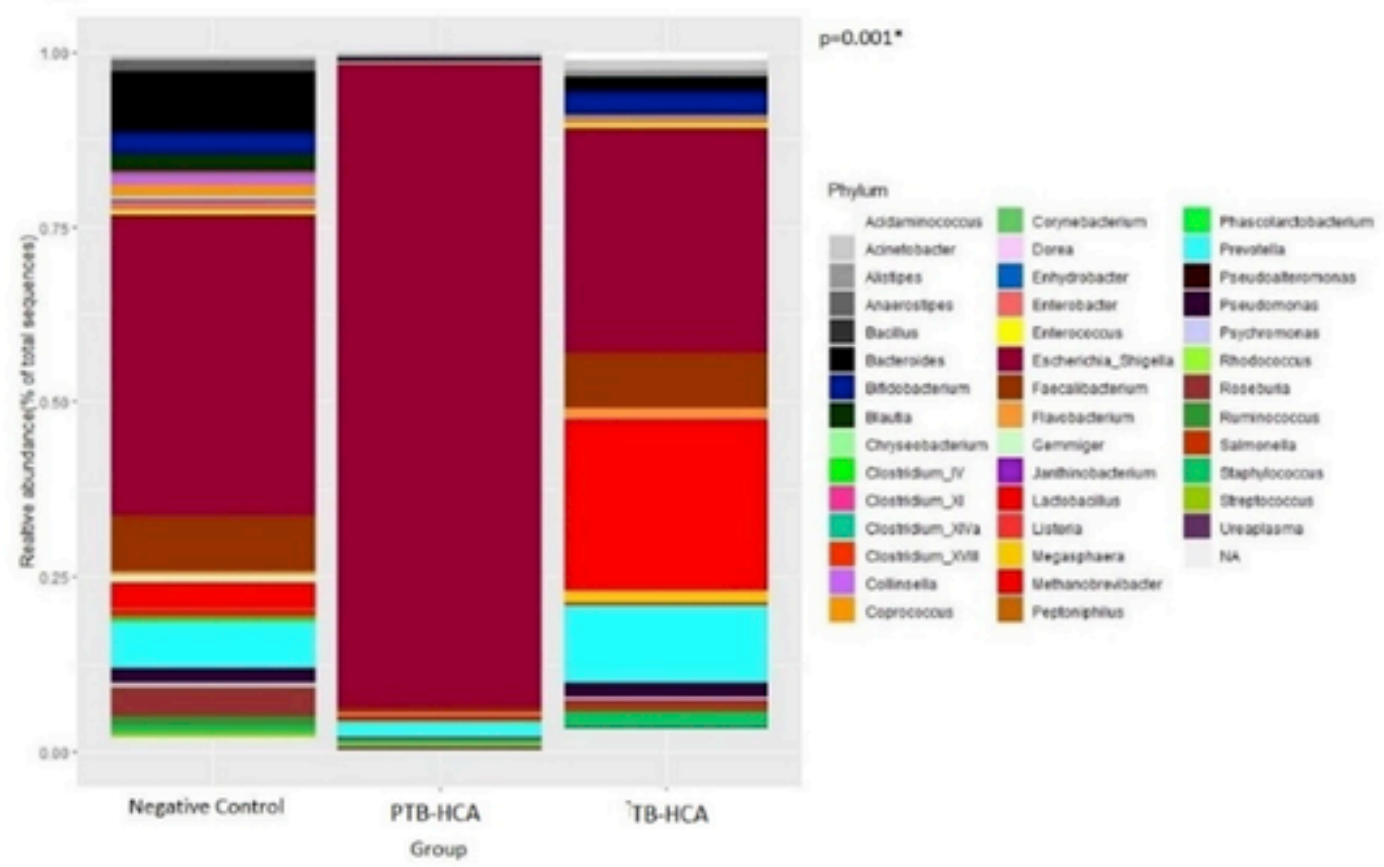

B

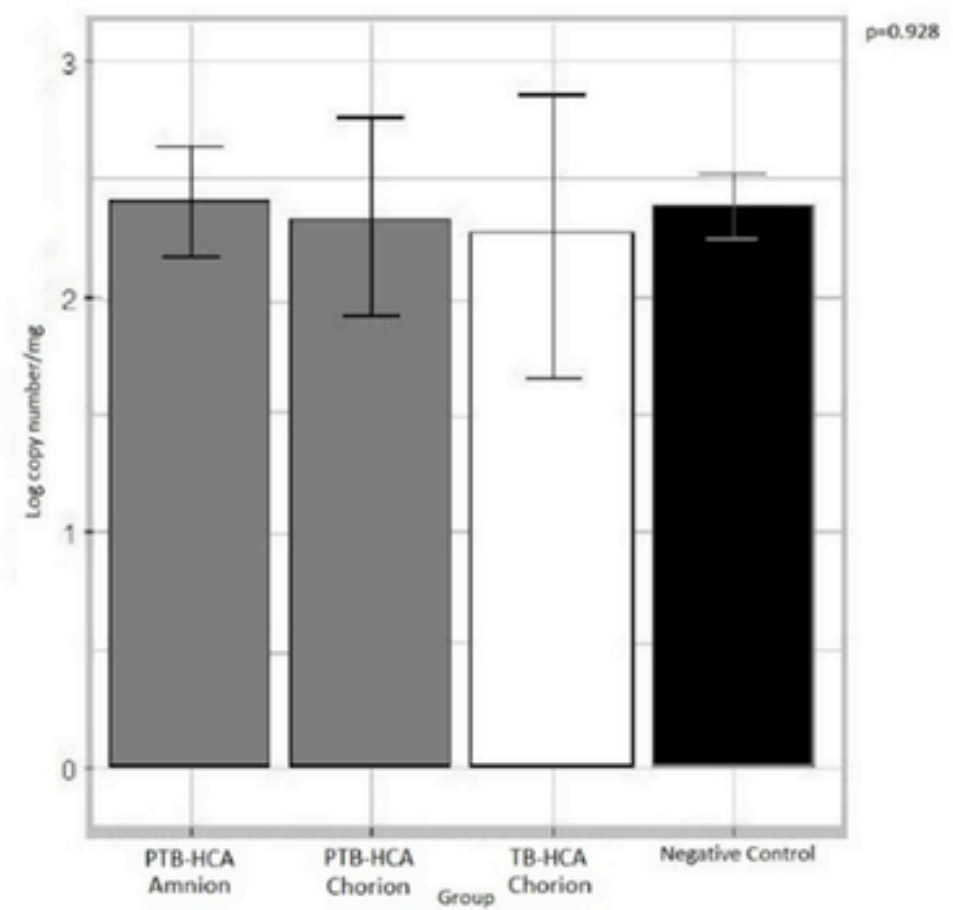

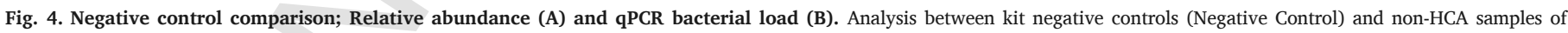

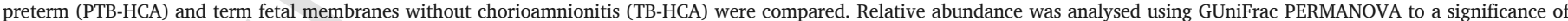

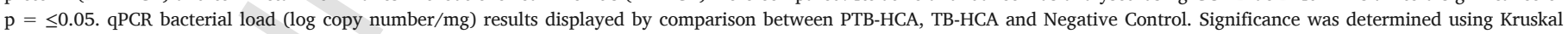
Wallis to a threshold of $\mathrm{p}=\leq 0.05$.

the same samples, with a correlation between the increase in TLR gene expression and HCA stage in both amnion and chorion [21]. Correlation between HCA bacterial load with TLR1/2 suggests that the number of gram-negative bacteria in the fetal membranes may be important in the development of HCA, as the TLR1/2 heterodimer recognises lipopeptides from gram negative bacteria. Although a trend was present, we were unable to identify significant differences in specific genera (in- cluding gram-negative bacteria) between groups. IL8 was the only inflammatory marker that correlated with bacterial load in both membranes. The IL8 ligand has been detected in greater concentrations from HCA patients compared to without HCA, as supported by Kacerovsky et al. (2009) [44]. IL8 levels have previously been used to predict HCA staging in amniotic fluid, with high specificity [45]. Alternatively, danger signals including HMGB1 also activate the TLR/MyD88 depen- 
dent pathway [46], known as the sterile inflammatory response theory [41]. However, our work suggests that bacterial load is the key driver to inflammation in the fetal membranes studied here.

Findings show that non-HCA samples and negative controls differ in few specific bacterial genera but display no difference in bacterial load. Previous studies have also detected genera originating mainly from negative controls, including Dorea and Pseudomonas when establishing bacterial profiles of placental samples $[18,47]$. These genera are suggested to be contaminants in low biomass research $[18,47]$, thus findings indicating clinical relevance of these bacteria are to be carefully analysed and ensure that correct methodology and negative controls have been included to avoid misinterpretation.

\subsection{Research and clinical implications}

Conflicting literature highlights the difficulty of reaching a conclusion on the fetal membrane microbiome in HCA $[2,16,23,46]$. Although a linear relationship between bacterial load and inflammation was detected here, the threshold overall bacterial load required to activate the inflammatory response warrants further study. Investigating selected inflammatory markers as potential biomarkers for HCA, including TLR signalling mediators, may be important, including a focus on LY96 (MD2) which links cell surface TLR to bacterial LPS. PPROM was the most prevalent cause of PTB, occurring in $75 \%$ of HCA and $50 \%$ of PTB patients, thus it may be of interest to investigate the variation in HCA between PPROM and SPTB. Additional research may also aim to understand the origin of bacteria using multiple body site analysis.

\subsection{Strengths and limitations}

The absence of a known healthy fetal membrane microbiome complicates the ability to determine a microbiome linked to HCA. Thus, fetal membranes without chorioamnionitis from preterm and term labour are required for within study comparisons, as incorporated into this study. The histological threshold for HCA was set at stage two inflammatory response. However, only one stage three sample was available from the HCA subgroup, limiting conclusions at this level. Excluding stage one subchorionitis ensures specificity to HCA rather than subclinical chorioamnionitis, and is an established reproducible diagnostic criterion for HCA. Other studies may have included stage one, leading to different conclusions as to the role of infection and inflammation in HCA.

The fetal membrane is a low biomass sample [45,47], which increases the risk of contamination [48]. To minimise this, negative controls were included and compared to samples and all samples displayed progressive labour, limiting variation. A 24-patient sample set from one tertiary unit was utilised increasing consistency of sample handling. A larger sample set would have strengthened findings to cover heterogeneity of maternal and fetal response, though the low incidence of early preterm birth and HCA is a recognised challenge in this field of research. For a subset of patients only amnion or chorion were available, which could bias results and is a known limitation of human tissue collection. Bacterial origin cannot be determined as only fetal membrane samples were analysed. The inclusion of vaginal, oral, skin and blood samples would allow greater understanding of the source of bacteria and allow further investigation into the link between reproductive, placental and fetal membrane health [49].

\section{Conclusions}

The data indicates that inflammation of the fetal membranes is associated with infection and increased bacterial load in a dose dependent relationship, rather than specific bacterial profiles. Bacterial load is positively correlated to HCA severity and activation of the TLR sig- nalling pathway. Further research investigating the bacterial threshold level required to generate an inflammatory response leading to HCA requires attention.

\section{Funding}

This work was funded by a grant from the British Maternal and Fetal Medicine Society awarded to Dr Waring and Dr Nelson and supported by the Teesside University Graduate Tutor Scheme with resources provided by the School of Health and Life Sciences.

\section{Details of ethical approval}

The samples were utilised for current research via a transfer agreement, with prior approval from Newcastle and North Tyneside 1 Research Ethics Committee (Ref:10/H0906/71).

\section{Contribution to authorship}

RH was responsible for qPCR planning, execution, data analysis and interpretation, plus analysis and interpretation of the NGS data, also for drafting the manuscript. GW designed the study, was involved in approval, tissue collection and providing data and analysis for the correlation section. GT and CO were involved in the design, monitoring and support of the study. CO was also involved in qPCR planning. SPC and SCR were responsible for the initial concept and approval for the study. AN was responsible for planning and design of the study, executing the NGS method and support of the study. All authors critically revised the manuscript and gave final approval for publication.

\section{Declaration of competing interest}

The Author(s) declare(s) that there is no conflict of interest.

\section{Acknowledgements}

Acknowledgments are made to The Royal Victoria Infirmary (RVI), Newcastle Upon Tyne for allowing collection and access to the tissue samples, also to Dr Judith Bulmer and fellow clinicians at the RVI for collecting and processing samples.

\section{References}

[1] A.T.N. Tita, W.W. Andrews, Diagnosis and management of clinical chorioamnionitis, Clin. Perinatol. 37 (2) (2010) 339-354, doi:10.1016/j.clp.2010.02.003.

[2] E.L. Sweeney, S.G. Kallapur, T. Gisslen, D.S. Lambers, C.A. Chougnet, S.A. Stephenson, A.H. Jobe, C.L. Knox, Placental infection with Ureaplasma species is associated with histologic chorioamnionitis and adverse outcomes in moderately preterm and late-preterm infants, J. Infect. Dis. 213 (8) (2016) 1340-1374, doi:10.1093/infdis\%2Fjiv587.

[3] D.H. Taft, N. Ambalavanan, K.R. Schibler, Z. Yu, D.S. Newburg, H. Deshmukh, D.V. Ward, A.L. Morrow, Centre variation in intestinal microbiota prior to late-onset sepsis in preterm infants, PloS One 10 (6) (2015), doi:10.1371/ journal.pone.0130604 e0130604.

[4] T. Strunk, C. Campbell, D. Burgner, A. Charles, N. French, M. Sharp, K. Simmer, E. Nathan, D. Doherty, Histological chorioamnionitis and developmental outcomes in very preterm infants, J. Perinatol. 39 (2) (2018) 321-330, doi:10.1038/ s41372-018-0288-3.

[5] M.M. Lahra, H.E. Jeffery, A fetal response to chorioamnionitis is associated with early survival after preterm birth, AJOG 190 (1) (2004) 147-151, doi:10.1016/ j.ajog.2003.07.012.

[6] J.S. Leiby, K. McCormick, S. Sherrile-Mix, E.L. Clarke, L.R. Kesslet, L.J. Taylor, C.E. Hofstaedter, A.M. Roche, L.M. Mattei, K. Bittinger, M.A. Elovitz, R. Leite, S. Parry, F.D. Bushman, Lack of detection of a human placenta microbiome in samples from preterm and term deliveries, Microbiome 6 (196) (2015), doi:10.1186/ s40168-018-0575-4.

[7] L.J. Funkhouser, S.R. Bordenstein, Mom knows best: the universality of maternal microbial transmission, PLoS Biol. 11 (8) (2013), doi:10.1371/ journal.pbio.1001631 e1001631.

[8] K.R. Theis, R. Romero, A.D. Winters, J.M. Greenberg, N. Gomez-Lopez, A. Alhousseini, J. Bieda, E. Maymon, P. Pacora, J.M. Fettweis, G.A. Buck, K.K. Jefferson, J.F. Strauss III, O. Erez, S.S. Hassan, Does the human placenta delivered at term have a microbiota? Results of cultivation, quantitative real-time PCR, 16S RRNA gene sequencing, and metagenomics, AJOG 220 (3) (2019) 267e.1-267.e39, doi:10.1016/j.ajog.2018.10.018.

[9] A.A. Kuperman, A. Zimmerman, A. Hamadia, O. Ziv, V. Gurevich, B. Fichtman, N. Gavert, r Straussman, H. Rechnitzer, M. Bazilay, S. Shvalb, J. Bornstein, I. Ben- 
Scachae, S. Yagel, I. Haviv, O. Koren, Deep microbial analysis of multiple placentas shows no evidence for a placental microbiome, BJOG (2019) Epub ahead of print], doi:10.1111/1471-0528.15896.

[10] R. McCuaig, D. Wong, F.W. Gardiner, W. Rawlinson, J.E. Dahlstrom, R.S. Robson, Periodontal pathogens in the placenta and membranes in term and preterm birth, Placenta 68 (2018) 40-43, doi:10.1016/j.placenta.2018.06.310.

[11] M.D. Seferovic, A.L. Prince, D.M. Chu, A.G. Sweeney, M.A. Engevik, P.B. Ganesh, N. Andrews, J. Versalovic, K. Aagaard, Recovery of placental bacteria is facilitated by periodontitis in orally inoculated germ-free mice, AJOG 214 (1) (2016) s144, doi:10.1016/j.ajog.2015.10.282

[12] R.N. Fichorova, A.B. Onderdonk, H. Yamamoto, M.L. Delaney, A.M. DuBois, E. Allred, A. Leviton for the extremely low gestation age newborns (ELGAN) study investigators, maternal microbe-specific modulation of inflammatory response in extremely low-gestational-age newborns, mBio 2 (1) (2011) e00280-10, doi:10.1128/mBio.00280-10.

[13] J. Bassols, M. Serino, G. Carreras-Badosa, R. Burcelin, V. Blasco-Baque, A. Lopez-Bermejo, J.-M. Fernandez-Real, Gestational diabetes is associated with changes in placental microbiota and microbiome, Paediatr. Res. 80 (6) (2016) 777-784, doi:10.1038/pr.2016.155.

[14] K. Aagaard, J. Ma, K.M. Antony, R. Ganu, J. Petrosino, J. Versalovic, The placenta harbours a unique microbiome, Sci. Transl. Med. 6 (237) (2014) 127ra65, doi:10.1126/scitranslmed.3008599.

[15] A.L. Prince, J. Ma, P.S. Kannen, T. Gisslen, R.A. Harris, E.L. Sweeney, C.L. Knox, D.S. Lambers, A.H. Jobe, C.A. Chougnet, S.G. Kallapur, K.M. Aagaard, The placen tal membrane microbiome is altered among subjects with spontaneous preterm birth with and without chorioamnionitis, AJOG 214 (627) (2016) e1-627 e16, doi:10.1016/j.ajog.2016.01.193.

[16] R.M. Doyle, K. Harris, S. Kamiza, U. Hrjunman, U. Ashorn, M. Nkhoma, K.G. Dewey, K. Maleta, P. Ashorn, N. Klein, Bacterial communities found in placental tissues are associated with severe chorioamnionitis and adverse birth outcomes, PloS One 12 (7) (2014), doi:10.1371/journal.pone.0180167 e0180167.

[17] J.L. Hecht, A. Onderdonk, M. Delaney, E.N. Allred, H.J. Kliman, E. Zambrano, S.M. Pflueger, C.A. Livasy, I. Bhan, A. Lviton, Characterization of chorioamnionitis in 2nd-trimester c-section placentas and correlation with microorganism recovery from subamniotic tissues, Paediatr. Dev. Pathol. 11 (1) (2009) 15-22, doi:10.2350/07-06-0285.1.

[18] M.C. de Goffau, S. Lager, U. Sovio, F. Gaccioli, E. Cook, S.J. Peacock, J. Parkhill, D.S. Charnock-Jones, G.C.S. Smith, Human placenta has no microbiome but can contain potential pathogens, Nature 572 (7769) (2019) 329-334, doi:10.1038/ s41586-019-1451-5.

[19] M.J. Kim, R. Romero, M.T. Gervasi, J.-S. Kin, W. Yoo, D.-C. Lee, P. Mittal, O. Erez J.P. Kusanovic, S.S. Hassan, C.J. Kim, Widespread microbial invasion of the chorioamniotic membranes is a consequence and not a cause of intra-amniotic infection, Lab. Invest. 89 (8) (2009) 924-936, doi:10.1038/labinvest.2009.49.

[20] H.E. Jones, K.A. Harris, M. Azizia, L. Bank, B. Carpenter, J. C Hartley, N. Klein, D. Peebles, Differing prevalence and diversity of bacterial species in fetal membrane from very preterm and term labor, PloS One 4 (12) (2009), doi:10.1371/ journal.pone.0008205 e8205.

[21] G.J. Waring, S.C. Robson, J.N. Bulmer, A.J. Tyson-Capper, Inflammatory sig nalling in fetal membranes: increased expression levels of TLR 1 in the presence of preterm histological chorioamnionitis, PloS One 10 (5) (2015), doi:10.1371/ journal.pone.0124298 e0124298.

[22] D.C. Kasper, T.P. Mechtler, G.H. Reischer, A. Witt, M. Langgartner, A. Pollak, K.R Herkner, A. Berger, The bacterial load of Ureaplasma parvum in amniotic fluid is correlated with an increased intrauterine inflammatory response, Diagn. Microbiol. Infect. Dis. 67 (2) (2010) 117-121, doi:10.1016/j.diagmicrobio.2009.12.023.

[23] D.J. Roberts, A.C. Celi, J.E. Riley, A.B. Onderdonk, T.K. Boyd, L.C. Johnson, E. Lieberman, Acute histological chorioamnionitis at term: nearly always non-infectious, PloS One 7 (3) (2012), doi:10.1371/journal.pone.0031819 e31819.

[24] R. Menon, R.N. Taylor, S.J. Fortunato, Chorioamnionitis- A complex pathophysiological syndrome, Placenta 31 (2) (2010) 113-120, doi:10.1016/ j.placenta.2009.11.012

[25] D. Dudzik, R. Revello, C. Barbas, J.L. Bartha, LC-MS based metabolomics identification of novel biomarkers of chorioamnionitis and its associated perinatal neurological damage, J. Proteome Res. 14 (3) (2015) 1432-1444, doi:10.1021/ pr501087x.

[26] V. Tambor, M. Vajrychova, M. Kacerovsky, M. Link, P. Domasinska, R. Menon, J. Lenco, Potential peripartum markers of infectious-inflammatory complications in spontaneous preterm birth, BioMed Res. Int. (2015) 343501, doi:10.1155/2015/ 343501.

[27] R.W. Redline, O. Faye-Petersen, D. Heler, F. Qureshi, V. Savell, C. Vogler, The society for pediatric pathology, perinatal section, amniotic fluid infection nosology committee, amniotic infection syndrome: nosology and reproducibility of placental reaction patterns, Paediatr. Dev. Pathol. 6 (5) (2003) 435-448, doi:10.1007/ s10024-003-7070-y.

[28] C.M. Liu, M. Aziz, S. Kachur, P.-O. Hsueh, Y.-T. Huang, P. Keim, L.B. Price, BactQuant: an enhanced broad-coverage bacterial quantitative real-time PCR assay, BMC Microbiol. 12 (56) (2012), doi:10.1186/1471-2180-12-56.
[29] J.J. Kozich, S.L. Westcott, N.T. Baxter, S.K. Highlander, P.D. Schloss, Development of a dual-index sequencing strategy and curation pipeline for analysing amplicon sequence data on the MiSeq Illumina sequencing platform, Appl. Environ. Microbiol. 79 (17) (2013) 5112-5120, doi:10.1128/AEM.01043-13.

[30] G. Biesbroek, E.A.M. Sanders, G. Roeselers, X. Wang, M.P.M. Caspers, K. Trzcinski, D. Bogaert, B.J.F. Keijser, Deep sequencing analyses of low-density microbial communities: working at the boundary of accurate microbiota detection, PloS One 7 (3) (2012), doi:10.1371/journal.pone.0032942 e32942.

[31] B.J. Callahan, P.J. McMurdie, M.J. Rosen, A.W. Han, A.J.A. Johnson, S.P. Holmes, DADA2: high resolution sample inference from Illumina amplicon data, Nat. Methods 13 (7) (2016) 581-583, doi:10.1038/nmeth.3869.

[32] B. Callahan, K. Sankaran, J.A. Fukuyama, P.J. McMurdie, Bioconductor workflow for microbiome data analysis: from to reads to community analyses, F1000 Res. 5 (2016) 1492, doi:10.12688/f1000research.8986.2.

[33] B.J. Callahan, P.J. McMurdie, S.P. Holmes, Exact sequence variants should replace operational taxonomic units in marker-gene data analysis, ISME J. 11 (12) (2017), doi:10.1038/ismej.2017.119.

[34] B. Callahan The RDP and GreenGenes taxonomic training sets formatted for DADA2[Data set], Zenodohttp://doi.org/10.5281/zenodo.1589552016

[35] R Core Team, R: A Language and Environment for Statistical Computing, R Foundation for Statistical Computing, 2017 Available at:. https://www.R-project.org/.

[36] IBM Corp, IBM SPSS Statistics for Windows, IBM Corp, Armonk, NY, 2017 Version 25.0

[37] P.J. McMurdie, S. Holmes, Phyloseq: an R package for reproducible interactive analysis and graphics of microbiome census data, PloS One 8 (4) (2013), doi:10.1371/journal.pone.0061217 e61217.

[38] C.E. Shannon, A mathematical theory of communication, Bell Labs Tech. J. 27 (3) (1948) 379-423, doi:10.1002/j.1538-7305.1948.tb01338.x.

[39] R. Knight, A. Vrbanac, B.C. Taylor, A. Aksenov, C. Callewaert, J. Debelius, A. Gonzalez, T. Kosciolek, L.I. McCall, D. McDonald, A.V. Melnik, J.T. Morton, J. Navas, R.A. Quinn, J.G. Sanders, A.D. Swafford, L.R. Thompson, A. Tripathi, Z.Z. Xu, J.R. Zaneveld, Q. Zhu, J.G. Caporaso, P.C. Dorrestein, Best practice for analysing microbiomes, Nat. Rev. Microbiol. 16 (7) (2015) 410-422, doi:10.1038/ s41579-018-0029-9.

[40] I. Musilova, R. Kitova, L. Pliskova, M. Stepan, R. Menon, B. Jacobsson, M. Kacerovsky, Intraamniotic inflammation in women with preterm prelabor rupture of membranes, PloS One 10 (7) (2015), doi:10.1371/journal.pone.0133929 e0133929.

[41] R. Romero, J. Miranda, T. Chaiworapongsa, S.J. Korzeniewski, P. Chaemsaithong, F. Gotsch, Z. Dong, A.I. Ahmed, B.H. Yoon, S.S. Hassan, C.J. Kim, L. Yeo, Prevalence and clinical significance of sterile intra-amniotic inflammation in patients with preterm labor and intact membranes, AJOG 72 (5) (2014) 458-474, doi:10.1111/aji.12296.

[42] D. Urushiyama, W. Suda, E. Ohnishi, R. Araki, C. Kiyoshima, M. Kurakazu, A. Sanui, F. Yotsumoto, M. Murata, K. Nabeshima, S. Yasunaga, S. Saito, M. Nomiyama, M. Hattori, S. Miyamoto, K. Hata, Microbiome profile of the amniotic fluid as a predictive biomarker of perinatal outcome, Sci. Rep. 7 (12171) (2017), doi:10.1038/s41598-017-11699-8.

[43] B.W. Kramer, T.J. Moss, K.E. Willet, J.P. Newham, P.D. Sly, S.G. Kallapur, M. Ikegami, A.H. Jobe, Dose and time response after intraamniotic endotoxin in preterm lambs, Am. J. Respir. Crit. Care Med. 164 (3) (2001) 982-988, doi:10.1164/ajrccm.164.6.2103061.

[44] M. Kacerovsky, M. Drahosova, H. Hornychova, L. Pliskova, R. Bolehovska, M. Forstl, J. Tosner, C. Andrys, Value of amniotic fluid interleukin-8 for the prediction of histological chorioamnionitis in preterm premature rupture of membranes, Neuroendocrinol. Lett. 30 (6) (2009) 733-738.

[45] S. Yoneda, A. Shiozaki, M. Ito, N. Yoneda, K. Inada, R. Yonezawa, M. Kigawa, S. Saito, Accurate prediction of the stage of histological chorioamnionitis before delivery by amniotic fluid IL-8 level, Am. J. Reprod. Immunol. 73 (6) (2015) 568-576, doi:10.1111/aji.12360.

[46] S.J. Salter, M.J. Cox, E.M. Turek, S.T. Calus, W.O. Cookson, M.F. Moffatt, P. Turner, J. Parkhill, N.J. Loman, A.W. Walker, Reagent and laboratory contamination can critically impact sequence-based microbiome analyses, BMC Biol. 12 (87) (2014), doi:10.1186/s12915-014-0087-z.

[47] T. Kawai, S. Akira, The role of pattern-recognition receptors of innate immunity: update on Toll-like receptors, Nat. Immunol. 11 (5) (2010) 373-384, doi: $10.1038 /$ ni. 1863

[48] A. Glassing, S.E. Dowd, S. Galandiuk, B. Davis, R.J. Chiodini, Inherent bacterial DNA contamination of extraction and sequencing reagents may affect interpretation of microbiota in low bacterial biomass samples, Gut Pathog. 8 (24) (2016), doi:10.1186/s13099-016-0103-7.

[49] R. Romero, S.S. Hassan, P. Gajer, A.L. Tarca, D.W. Fadroch, L. Nikita, M. Galuppi, R.F. Lamont, P. Chaemsaithong, J. Miranda, T. Chaiworapongsa, J. Ravel, The composition and stability of the vaginal microbiota of normal pregnant women is different from that of non-pregnant women, Microbiome 2 (4) (2014), doi:10.1186/2049-2618-2-4. 